PONTIFÍCIA UNIVERSIDADE CATÓLICA DO RIO DE JANEIRO

Estudo sobre a Viabilidade Econômica de um Clube de Poker no Rio de Janeiro

Daniel Neuman Kessel

Trabalho de Conclusão de Curso

Centro de ciências socials - CCS

DEPARTAMENTO DE ADMINISTRAÇÃO

Graduação em Administração de Empresas 
Daniel Neuman Kessel

\section{Estudo sobre a Viabilidade Econômica de um Clube de Poker no Rio de Janeiro}

Trabalho de Conclusão de Curso

Trabalho de Conclusão de Curso, apresentado ao programa de graduação em Administração da PUC-Rio como requisito parcial para a obtenção do titulo de graduação em Administração.

Orientador: André Cabús Klötzle

Rio de Janeiro

Junho de 2018 


\section{Resumo}

Neuman Kessel, Daniel. Estudo sobre a Viabilidade Econômica de um Clube de Poker no Rio de Janeiro. Rio de Janeiro, 2018. 24 p. Trabalho de Conclusão de Curso - Departamento de Administração. Pontifícia Universidade Católica do Rio de Janeiro.

A motivação para a elaboração deste trabalho é o crescimento da prática e de negócios relacionados ao poker no Brasil. Hoje, mais de 7 milhões de pessoas praticam o jogo no país e a geração de empreendimentos e empregos em torno dessa realidade é constante. Com esta perspectiva, pode-se dizer que ainda há espaço para crescer até que o mercado atinja o seu potencial no Brasil.

Considerando esta situação, a partir do levantamento de dados foi analisada a viabilidade em termos financeiros de operar um clube de poker no Rio de Janeiro ao longo de 20 anos. Para isso, foi utilizada a metodologia de Fluxo de Caixa Descontado, e os principais indicadores envolvidos são o Valor Presente Líquido (VPL) e a Taxa Interna de Retorno (TIR), como critérios primários, além do Payback e Payback Descontado, como métodos secundários.

Palavras-chave:

Poker, Clube, Viabilidade, VPL, TIR, Fluxo de Caixa Descontado 


\section{Abstract}

Neuman Kessel, Daniel. Study on the Economic Viability of a Poker Club in Rio de Janeiro. Rio de Janeiro, 2018. 24 p. Trabalho de Conclusão de Curso - Departamento de Administração. Pontifícia Universidade Católica do Rio de Janeiro.

The key motivation for this work is an increasing national inclination for the practice of poker and businesses related to it. Nowadays, over 7 million people practice the game in Brazil, contributing with employment generation and businesses development. With this view, it is possible to say that the market still hasn't reached its full potential in the country.

Given this situation, the financial viability to operate a poker club in Rio de Janeiro for 20 years was analysed. For this purpose, the Discounted Cash Flow methodolgy was used, and the main indicators involved were Net Present Value, Internal Rate of Return, Payback and Discounted Payback.

Key-words:

Poker, Club, Viability, NPV, IRR, Discounted Cash Flow 


\section{Sumário}

1 O tema e o problema do estudo 1

1.1. Introdução ao tema e ao problema do estudo 1

1.2. Objetivo do estudo 1

1.3. Objetivos intermediários do estudo 2

1.4. Delimitação e foco do estudo 2

1.5. Justificativa e relevância do estudo 2

2 Contexto do Mercado de Poker 3

2.1. O Boom do Poker no Brasil 3

2.2. Os Clubes 4

2.3. Regulamentação 4

3 Referencial Teórico $\quad 6$

3.1. Fluxo de Caixa Descontado 6

3.2. Taxa de Desconto 7

3.2.1. Custo do Capital Próprio

3.2.2. Custo Médio Ponderado de Capital 8

3.3. Valor Presente Líquido (VPL) 8

3.4. Taxa Interna de Retorno (TIR) 9

3.5. Payback 9

$\begin{array}{lr}\text { 3.6. Payback Descontado } & 10\end{array}$

4 Metodologia 11

5 Estudo de Caso de um Clube de Poker e Resultados 12

5.1. Premissas de Investimento 12

5.2. Projeção de Receitas 13

$\begin{array}{ll}\text { 5.2.1. Receitas } & 13\end{array}$

5.2.2. Receita Projetada 14

5.3. Projeção de Custos e Despesas 15 
5.3.1. Tributação 15

5.3.2. Despesas 16

5.3.3. Depreciação 16

5.4. Custo de Capital 16

5.4.1. Custo do Capital Próprio (CAPM) 16

5.5. Projeção de Resultados 18

$\begin{array}{ll}\text { 5.5.1. Fluxo de Caixa dos Ativos } & 18\end{array}$

$\begin{array}{ll}\text { 5.5.2. Indicadores Financeiros } & 20\end{array}$

6 Conclusões e Recomendações para Novos Estudos 21

7 Referências Bibliográficas $\quad 22$ 


\section{0 tema e o problema do estudo}

\subsection{Introdução ao tema e ao problema do estudo}

A regulação da prática do poker do Brasil ainda não é totalmente satisfatória. Ainda assim, o mercado em torno do jogo não para de crescer, impulsionado, principalmente, pela possibilidade de diversão, competitividade, adrenalina e ganhos financeiros.

Segundo dados de 2016 da CBTH (Confederação Brasileira de Texas Hold'em), há 7 milhões de praticantes do jogo no Brasil contra 5 milhões em 2013, ou seja, uma taxa de crescimento expressiva. Além disso, outro dado que chama atenção é o torneio mais importante do país ter tido 100 participantes no ano de sua criação (2006) e mais de 1.500 em 2017.

Essa realidade reforça uma tendência de existirem cada vez mais estabelecimentos dedicados à prática do jogo e, nesse ponto, os números também impressionam. São mais de 500 espaços que oferecem atualmente mesas de poker no país com seus próprios dealers, fichas, baralhos e todos os acessórios necessários. Aproximadamente $15 \%$ se localizam em São Paulo, mas há 22 estados que contam com federações.

Uma regulamentação completa do poker enquanto negócio é o que falta para que empresários possam empreender e realizar projetos nessa área com a segurança jurídica adequada. A atual legalidade é indiscutível e a completa regulamentação, inevitável. Os que estiverem mais preparados poderão se antecipar e aproveitar a novidade.

Assim, este trabalho pretende responder à seguinte pergunta: "É economicamente viável iniciar um clube de poker hoje no Rio de Janeiro?".

\subsection{Objetivo do estudo}

O objetivo final deste estudo é verificar a viabilidade econômico-financeira de um clube de poker no Rio de Janeiro, com base em premissas estabelecidas acerca da situação atual e perspectivas para o futuro. 


\subsection{Objetivos intermediários do estudo}

Em primeiro lugar, será necessário que se definam premissas para estimar as receitas e gastos do projeto.

Então, será possível projetar os fluxos de caixa ao longo do tempo e calcular os indicadores financeiros que irão possibilitar as análises acerca da viabilidade do empreendimento.

\subsection{Delimitação e foco do estudo}

Este estudo é voltado para o mercado da cidade do Rio de Janeiro com uma projeção para os próximos 20 anos.

\subsection{Justificativa e relevância do estudo}

O crescimento da prática do poker enquanto esporte, tanto por jogadores recreativos, quanto por profissionais, é a principal relevância para o estudo do tema.

Trata-se de um mercado que movimenta milhões de dólares anualmente, com uma tendência clara de crescimento. Os números impressionam e os indícios apontam para uma possível oportunidade de negócio.

No entanto, como qualquer mercado em construção, há a necessidade de se avaliar determinados aspectos para verificar a real viabilidade do negócio. No caso dos clubes de poker, não é diferente.

O estudo é importante para que se compreenda a geração de receita, os custos envolvidos, a questão tributária, as oportunidades e os desafios que os empreendedores enfrentam e enfrentarão. 


\section{Contexto do Mercado de Poker}

\subsection{O Boom do Poker no Brasil}

No dia 18 de outubro de 2015, o Jornal "O Globo", que possui grande relevância nacional, publicou uma matéria com o título "Não é Sorte: O Boom do Pôquer no Brasil" (Figura 1). A matéria tratava sobre os impressionantes números do BSOP daquele ano, o maior torneio de poker do Brasil, que distribuiu, naquela oportunidade, mais de $\mathrm{R} \$ 24$ milhões em prêmios.

A reportagem trazia, ainda, outros dados surpreendentes. Falava sobre 0 crescimento exponencial do jogo nos Estados Unidos nos últimos 20 anos e dizia que, a despeito da crise financeira que assolava o Brasil naquele momento, o mercado do poker se expandia com cada vez mais força no país. Prova disso é o próprio BSOP, onde o número de participantes cresce ano após ano (Figura 2).

Figura 1: Matéria do Jornal "O Globo"

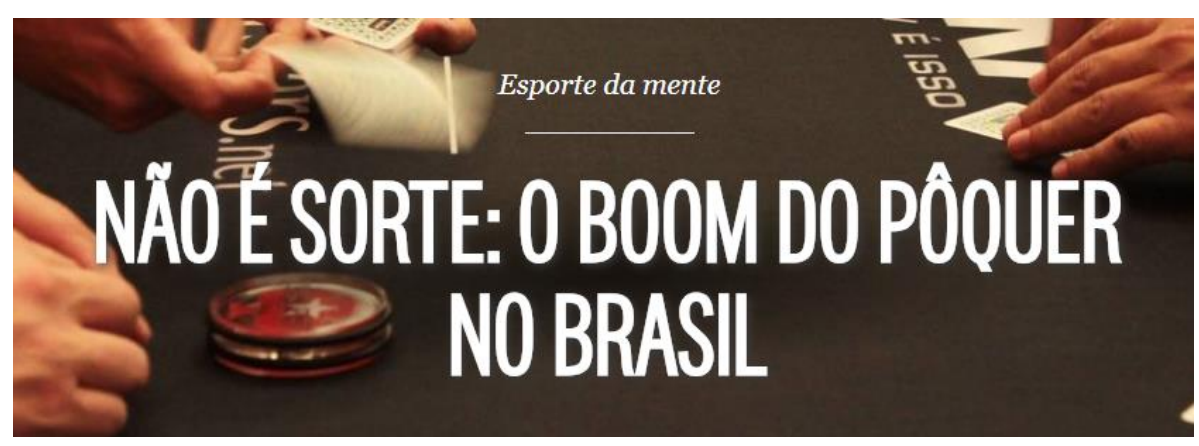

Fonte: Jornal O Globo, 2015

Figura 2

Média de jogadores por etapa no BSOP

(Campeonato Brasileiro de Poker)

PọkerStars net

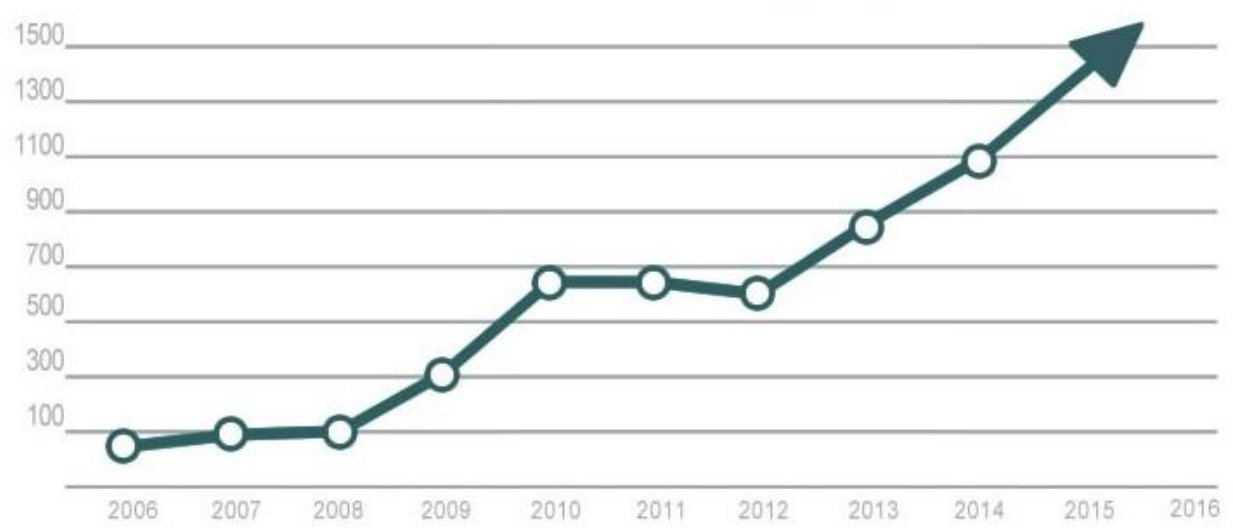

Fonte: Site Oficial do BSOP 


\subsection{Os Clubes}

A Folha, importante meio de comunicação, publicou no dia 12 de dezembro de 2016 uma reportagem dedicada ao tema específico da proliferação dos clubes (ou casas) de poker pelo Brasil.

Com o título "Clubes de pôquer crescem com público fiel e torneios diários" e fotos, a matéria explicou de maneira detalhada o funcionamento desse tipo de estabelecimento, e afirmou que o fato de o número de praticantes no país já ter passado de 7 milhões abre caminho para um novo mercado.

Funciona de maneiras simples. A casa cobra uma taxa de inscrição dos jogadores do torneio. Entre $15 \%$ e $20 \%$ fica com o local e o resto compõe a premiação da noite e será dividido entre os melhores colocados.

A reportagem conversou com Igor Trafane, presidente da CBTH (Confederação Brasileira de Texas Hold'em) à época, que disse haver mais de 500 casas desse tipo pelo Brasil. O empresário Denis de Andrade, também entrevistado, afirmou ter comprado $30 \%$ de um clube em Campinas por $R \$ 60$ mil em 2014 e que naquele momento, em 2016, não venderia por menos de $\mathrm{R} \$ 1$ milhão.

\subsection{Regulamentação}

A regulamentação dos jogos de poker no Brasil avança de maneira rápida. O jogo de azar é aquele que depende de forma predominante da sorte do jogador, ou seja, a habilidade do participante no presente jogo não é de extrema relevância. No jogo de poker, apesar de existir o fator sorte, é a estratégia, a habilidade e a observação do comportamento do adversário durante o momento da partida que determina o resultado. De acordo com o brilhante jurista Miguel Reale Júnior:

Em suma, pode-se afirmar que no jogo de pôquer ganha aquele que combina lógica e sensibilidade, lógica para elaboração rápida de um juízo de probabilidades com as cartas abertas e o número de jogadores, devendo também avaliar as desistências ocorridas, ao que junta a necessidade de haver um poder de observação dos adversários e de saber dissimular sua própria situação. Por isso, ganha o jogo aquele que, não só calcula as probabilidades, mas, também, sabe o momento certo psicologicamente de "blefar" e vencer sem ter cartas para tanto, bem como o que sabe - momento de se retirar diante da constatação de que o adversário, por suas características, não está a blefar, mas aposta por possuir cartas valiosas. 
A jurisprudência vai no mesmo sentido:

O jogo de pôquer não é jogo de azar, pois não depende exclusiva ou principalmente da sorte (DL $\underline{3.688 / 41}$, art. $\underline{50}$, a), norma cujo rumo não pode ser invertido, como se dissesse que de azar é o jogo cujo ganho ou perda não depende exclusiva ou principalmente da habilidade. É o contrário. Diz que pode prevalecer o fator sorte, e não que deve prevalecer o fator habilidade. No pôquer, o valor real ou fictício das cartas depende da habilidade do jogador, especialmente como observador do comportamento do adversário, às vezes bastante sofisticado, extraindo daí informações que o leva a concluir se ele está, ou não, blefando. Não por acaso costuma-se dizer que o jogador de pôquer é um blefador. Por sua vez, esse adversário pode estar adotando certos padrões de comportamento, mas ardilosamente, isto é, para também blefar. Por exemplo, estando bem, mostra-se inseguro, a fim de o adversário aumentar a aposta, ou, estando mal, mostra-se seguro, confiante, a fim de o adversário desistir. Em suma, é um jogo de matemática e de psicologia comportamental. (Mandado de Segurança n. 70025424086, de Porto Alegre, Primeira Câmara Cível, rel. Des. Irineu Mariani, j. 17.12.2008).

É importante notar também que, nos torneios, não há aposta direta de dinheiro. Os participantes pagam pela inscrição um valor fixo e definido anteriormente ao início do torneio e, caso venha a ser bem sucedido, recebe sua premiação.

A insegurança jurídica e a falta de uma regulamentação completa e abrangente é a última barreira à explosão do jogo no país. No entanto, a jurisprudência favorável, o crescimento exponencial de adeptos, a tendência mundial e a força do mercado tornam inevitável que isso aconteça. 


\section{Referencial Teórico}

Neste capítulo, o objetivo é trazer os conceitos teóricos e metodológicos utilizados para o desenvolvimento do estudo e sua conclusão. Será desenvolvida, portanto, uma avaliação de fluxo de caixa descontado, com o objetivo de se analisar a viabilidade econômica de um clube de poker.

Não há uma única forma de se calcular o valor de uma empresa. No entanto, algumas metodologias são mais recorrentes, como os Múltiplos de Mercado e o Fluxo de Caixa Descontado (FCD). O primeiro, também conhecido como Modelo de Avaliação Relativa, de acordo com Martins (2008), mensura o valor da empresa a partir de comparações com outras. A comparação, para que seja efetiva, deve ser feita entre empresas similares e com a utilização de parâmetros como o EBITDA, lucro ou patrimônio líquido.

A utilização desta metodologia não é a ideal neste estudo, por conta da falta de informações financeiras sobre o mercado em questão, e pelo fato de se tratar de um novo tipo de negócio, regulamentado e legalizado há pouco tempo no país.

O FCD tem outro viés. Determina o valor de um projeto (como a abertura de uma empresa), em função de sua própria capacidade futura de geração de fluxos de caixa. Essa metodologia é, portanto, a mais indicada para o projeto e o contexto trabalhado.

\subsection{Fluxo de Caixa Descontado}

De acordo com Caio Galdi (2008), apud Copeland, Koller e Murrin (2000, p. 66), na técnica do FCD, o ponto de partida é estimar a geração de caixa da empresa, representada pelas receitas e gastos. Posteriormente, os ganhos ou perdas deverão ser ajustados levando em consideração a perda de valor do dinheiro ao longo do tempo e o risco previsto para o investimento, a chamada de taxa de desconto. A análise é baseada na percepção de que é mais atrativo e viável aquele projeto que apresenta o maior retorno para o mesmo nível de risco. 
Segundo Ross, Westerfield e Jordan (2013), há três principais etapas nessa metodologia. A primeira é a projeção dos fluxos de caixa futuros da empresa. É necessário, para isso, que se estabeleçam premissas baseadas na expectativa do mercado para algumas variáveis econômicas e financeiras, como, por exemplo, a demanda e o seu crescimento ao longo do tempo. Para que a perda de valor do dinheiro no tempo seja refletida, os fluxos de caixa devem ser trazidos a valor presente por meio da taxa de desconto. A conclusão é obtida através da análise dos indicadores derivados dos fluxos de caixa do período estudado. Os mais tradicionais são o Valor Presente Líquido (VPL) e a Taxa Interna de Retorno (TIR), como métodos primários de decisão, além do Payback e Payback Descontado, que são considerados métodos secundários. Esses indicadores serão brevemente detalhados ao longo deste capítulo.

\subsection{Taxa de Desconto}

\subsubsection{Custo do Capital Próprio}

Gitman (2010) diz que o retorno do acionista deve ser um produto do que for observado no mercado, adicionando ao risco do projeto. Assim, pode-se avaliar se há outras oportunidades com melhores rendimentos.

O modelo adequado para avaliar este retorno é o Capital Asset Pricing Model (CAPM). É a forma de se relacionar o risco atrelado ao mercado com o retorno exigido pelos acionistas. A medida é indicada por um fator $\beta$, que é um índice que representa a volatilidade do investimento e o risco atrelado ao mesmo.

Sua função no modelo é ajustar o chamado prêmio de risco esperado pelo acionista, que é a diferença entre o retorno médio do mercado e a taxa livre de risco, captando a sensibilidade a este prêmio de risco. Quando o $\beta$ for maior que 1 , o investimento é entendido como mais volátil e o prêmio de risco esperado é aumentado. Sendo o $\beta$ menor que 1, ocorre o oposto, o investimento é entendido como menos volátil e o prêmio de risco esperado é diminuído. A representação algébrica se dá por:

$$
R_{\mathrm{e}}=R_{f}+\left[\beta x\left(R_{m}-R_{f}\right)\right]
$$


Onde:

$\mathrm{R}_{\mathrm{e}}=$ Retorno esperado pelo acionista (custo do capital próprio)

$\mathrm{R}_{\mathrm{f}}=$ Taxa de juros livre de risco

$\beta=$ Índice de volatilidade (risco) atrelado ao negócio

$\mathrm{R}_{\mathrm{m}}=$ Taxa de retorno média do mercado

\subsubsection{Custo Médio Ponderado de Capital}

Segundo Copeland, Koller e Murrin (2002), o Custo Médio Ponderado de Capital pode ser entendido como a taxa que deve ser usada para realizar os descontos dos fluxos de caixa futuros e calcular, assim, os respectivos valores presentes. Partindo do princípio de que o primeiro objetivo é retornar o valor investido com os rendimentos mínimos, é possível utilizar o custo médio ponderado de capital (CMPC ou WACC, em inglês) como principal parâmetro.

É fundamental, para este cálculo, saber o custo do capital próprio e de terceiros, este último dado pelas condições do empréstimo, além da proporção entre eles em relação ao todo, como demonstrado abaixo:

$$
W A C C=\frac{E}{D+E} x C A P M+\frac{D}{D+E} x K d x(1-\mathrm{t})
$$

Onde:

$\mathrm{E}=$ Capital Próprio (Equity)

$\mathrm{D}=$ Capital de Terceiros (Dívida)

$\mathrm{t}$ = Alíquota do Imposto de Renda

$\mathrm{Kd}=$ Custo do Capital de Terceiros

\subsection{Valor Presente Líquido (VPL)}

O fundamento do VPL, segundo Ross, Westerfield e Jordan (2013), é a ideia de que todo investimento tem, como principal objetivo, a geração de valor para o acionista. Se essa premissa não for verdadeira, o investimento perde sua razão de ser.

O VPL é, na prática, uma forma de medir o valor agregado no presente de um investimento que será realizado no futuro, levando em conta os custos envolvidos. O ponto central é que, para ser aceito, o projeto deve ter VPL maior do que zero. É representado por: 


$$
V P L=\sum_{t=1}^{n} \frac{F C_{t}}{(1+i)^{t}}-I_{0}
$$

Onde:

$\mathrm{i}=$ Taxa de Desconto

$\mathrm{FC}_{t}=$ Fluxos de Caixa

$\mathrm{n}=$ Número de anos

$\mathrm{I}_{0}=$ Investimento inicial

$\mathrm{t}=$ Tempo em anos

\subsection{Taxa Interna de Retorno (TIR)}

A TIR é, segundo Ross, Westerfield e Jordan (2013), diretamente relacionada com o VPL. É "interna" por considerar apenas os fluxos de caixa do projeto, e é a taxa que iguala o VPL a zero.

A observação única e exclusiva deste indicador é uma análise limitada. Isto porque, ela não é capaz de definir o retorno mínimo exigido para a realização do projeto (taxa de desconto). Em resumo, nos casos em que a TIR for maior que a taxa de desconto, o projeto é aceito; senão, é rejeitado. Algebricamente, é representada por:

$$
-I_{0}+\sum_{t=1}^{n} \frac{F C_{t}}{(1+\mathrm{TIR})^{t}}=0
$$

\subsection{Payback}

Ross, Westerfield e Jordan (2013) definem o período de payback como "o tempo necessário para que um investimento gere fluxos de caixa suficientes para recuperar seu custo inicial". Ou seja, é a quantidade de tempo que o projeto leva para começar a gerar retornos que superem o que foi investido para a sua realização.

Para que seja possível tirar conclusões a partir do indicador, deve-se estipular o tempo limite aceitável, para servir de comparação. Por não levar em consideração os descontos ao longo do tempo, o indicador possui relevância contábil, mas não econômica. Dá-se, algebricamente, por: 


$$
\text { Payback }=\text { Tquando } \sum_{t=1}^{T} \quad F C_{t}=I_{0}
$$

\subsection{Payback Descontado}

Há a possibilidade de se incluir na formulação do payback o desconto do custo de capital ao longo do tempo. O indicador, desta maneira, passa a ser mais conservador, realista e prático. A representação algébrica é:

$$
\text { Payback Descontado }=\text { Tquando } \sum_{t=1}^{T} \frac{F C_{t}}{(1+i)}=I_{0}
$$




\section{Metodologia}

Conforme já exposto anteriormente, será desenvolvida uma avaliação de fluxo de caixa descontado, com o objetivo de se analisar a viabilidade econômica de um Clube de Poker no Rio de Janeiro. Este método leva em conta o Fluxo de Caixa Operacional (FCO) da empresa - portanto, desconsidera as receitas e despesas financeiras. Ou seja, parte do LAJIR, somando a depreciação (que não é saída de caixa) e descontando o imposto de renda. Deste fluxo, também serão abatidos os gastos de capital para investimentos de longo prazo (CAPEX) e os gastos líquidos com capital de giro (Variação do CG). Assim, chega-se ao fluxo de Caixa dos Ativos (FCA).

Ou seja: FCA = FCO (LAJIR + Depreciação - IR) - CAPEX - Var. do CG.

Este fluxo será obtido através de premissas de receitas, despesas e tributação. Também serão estipuladas premissas de investimento inicial e CAPM. Com base no investimento inicial e nos FCAs, descontados pelo WACC, serão obtidos o VPL e a TIR do projeto, a partir de onde será possível analisar sua viabilidade. Complementarmente, serão calculados o Payback e o Payback Descontado, para descobrir em quantos anos o investimento inicial será recuperado. 


\section{Estudo de Caso de um Clube de Poker e Resultados}

Neste capítulo, as premissas utilizadas para a projeção dos fluxos de caixa e resultados financeiros de um Clube de Poker no Rio de Janeiro serão detalhadas, para que seja possível a análise de viabilidade do negócio.

\subsection{Premissas de Investimento}

Os valores, baseados em empreendimentos similares realizados no Rio de Janeiro e São Paulo, estão discriminados na tabela 1 a seguir. O terreno e a construção representam a maior parcela dos investimentos, $R \$ 451.182,00$. O restante, equivalente a $R \$ 83.605,00$, diz respeito a equipamentos necessários à operação do negócio e prática do jogo: 
Tabela 1: Investimento Inicial do Projeto

\begin{tabular}{|c|c|c|c|c|c|}
\hline Itens & Cus & to Unitário & Qtd & & Total \\
\hline Terreno & $\mathrm{R} \$$ & $180.000,00$ & 1 & $\mathrm{RS}$ & $180.000,00$ \\
\hline Construção & $\mathrm{R} \$$ & $271.182,00$ & 1 & $\mathrm{R} \$$ & $271.182,00$ \\
\hline Mesa de Poker & $\mathrm{R} \$$ & $1.170,00$ & 16 & $\mathrm{RS}$ & $18.720,00$ \\
\hline Mesa de Sinuca & $\mathrm{R} \$$ & $2.280,00$ & 2 & $\mathrm{R} \$$ & $4.560,00$ \\
\hline Mesa da Lan-House & $\mathrm{R} \$$ & 800,00 & 1 & $\mathrm{RS}$ & 800,00 \\
\hline Mesa do Escritório & $\mathrm{R} \$$ & 800,00 & 1 & $\mathrm{RS}$ & 800,00 \\
\hline Mesa da Recepção & $\mathrm{R} \$$ & 500,00 & 1 & $\mathrm{RS}$ & 500,00 \\
\hline Estante & $\mathrm{R} \$$ & 400,00 & 2 & $\mathrm{R} \$$ & 800,00 \\
\hline Cadeiras & $\mathrm{RS}$ & 180,00 & 176 & $\mathrm{R} \$$ & $31.680,00$ \\
\hline Porta de Detector de Metal & $\mathrm{R} \$$ & $3.800,00$ & 1 & $\mathrm{R} \$$ & $3.800,00$ \\
\hline Computador & $\mathrm{R} \$$ & $2.000,00$ & 2 & $\mathrm{RS}$ & $4.000,00$ \\
\hline Impressora & $\mathrm{R} \$$ & 600,00 & 1 & $\mathrm{R} \$$ & 600,00 \\
\hline Televisão & $\mathrm{R} \$$ & $2.860,00$ & 4 & $\mathrm{RS}$ & $11.440,00$ \\
\hline Acessórios para o Bar & $\mathrm{RS}$ & $1.000,00$ & 1 & $\mathrm{RS}$ & $1.000,00$ \\
\hline Fichas & $\mathrm{RS}$ & 160,00 & 6 & $\mathrm{RS}$ & 960,00 \\
\hline Capital de Giro & $\mathrm{RS}$ & $3.945,00$ & 1 & $\mathrm{RS}$ & $3.945,00$ \\
\hline TOTAL & - & & - & $\mathrm{RS}$ & $534.787,00$ \\
\hline
\end{tabular}

Fonte: Elaborada pelo autor

\subsection{Projeção de Receitas}

Para estimar as receitas do empreendimento ao longo dos 20 anos de projeção, foram assumidas premissas em relação ao crescimento do mercado.

\subsubsection{Receitas}

A base de cálculo utilizada na estimativa de receitas foi, inicialmente, 0 valor médio gasto por cliente por mês em inscrições (buy-ins) de torneios de poker. Ao calcular a média dos dados da pesquisa mercadológica realizada, chega-se ao valor de $\mathrm{R} \$ 500,00$. Dado que a taxa cobrada pelo Clube representa $20 \%$ do buy-in, chega-se ao valor de $\mathrm{R} \$ 100,00$.

Para o cálculo referente a quantos clientes o Clube receberá por mês, recorre-se aos dados da pesquisa de mercado realizada. O resultado é que, aproximadamente, 250 jogadores frequentarão o clube mensalmente no primeiro ano, gerando uma receita bruta anual de $R \$ 300.000,00$.

Baseando-se na exponencial disseminação do jogo pelo mundo e, especialmente, no Brasil, é possível prever um aumento da frequência para os próximos anos. 
Tabela 2: Crescimento Anual da Demanda

\begin{tabular}{|l|c|}
\hline Até 5 anos & $15 \%$ \\
\hline Entre 5 e 10 anos & $8 \%$ \\
\hline Após 10 anos & $4 \%$ \\
\hline
\end{tabular}

Fonte: Elaborada pelo autor

\subsubsection{Receita Projetada}

A cada período, em função do crescimento do mercado esperado, há um aumento da receita. O gráfico da receita esperada para os próximos 20 anos é apresentado adiante:

\section{Gráfico 1: Receita Bruta Projetada}

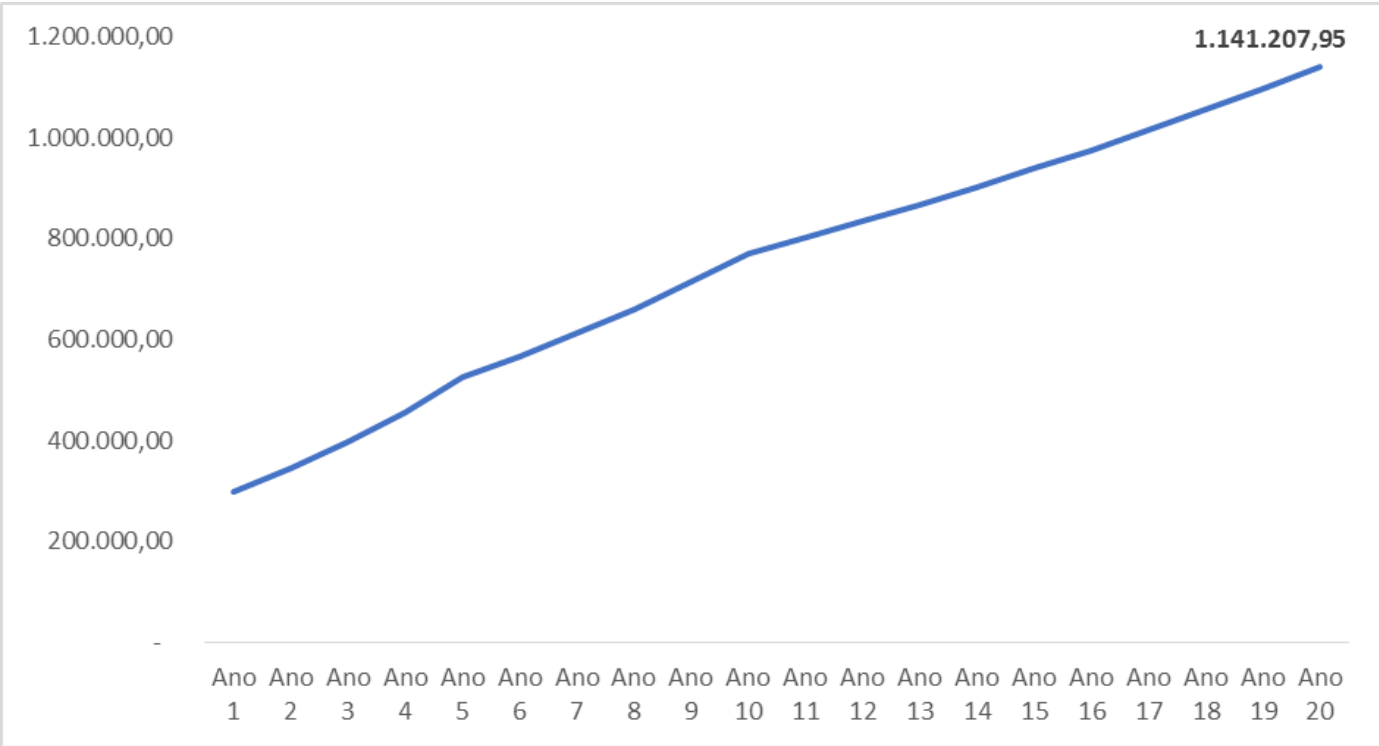

Fonte: Elaborado pelo autor 


\subsection{Projeção de Custos e Despesas}

Neste item os custos e despesas necessários para a operação do Clube serão detalhados. Assim como para as receitas, pesquisas mercadológicas embasaram premissas para estimar as saídas de caixa.

\subsubsection{Tributação}

Levando em consideração a possibilidade de, com a regulação completa do jogo, os clubes de poker serem incluídos no sistema de tributação do Simples Nacional, as regras deste sistema serão utilizadas para o cálculo de gastos com impostos.

De acordo com o Jornal Contábil (2017), as regras sobre inclusão de empresas, limites de faturamento e alíquotas do Simples Nacional serão (foram) modificadas a partir de 2018. Segundo o artigo, o faturamento máximo aumentou de $R \$ 3,6$ milhões para $R \$ 4,8$ milhões e a alíquota será maior, porém com um desconto previsto dependendo da faixa de faturamento da empresa. Estas informações estão descritas na tabela 3 a seguir, referente ao anexo III do Simples Nacional 2018, na qual estará enquadrado este tipo de negócio:

Tabela 3: Anexo III do Sistema de Tributação Simples Nacional 2018

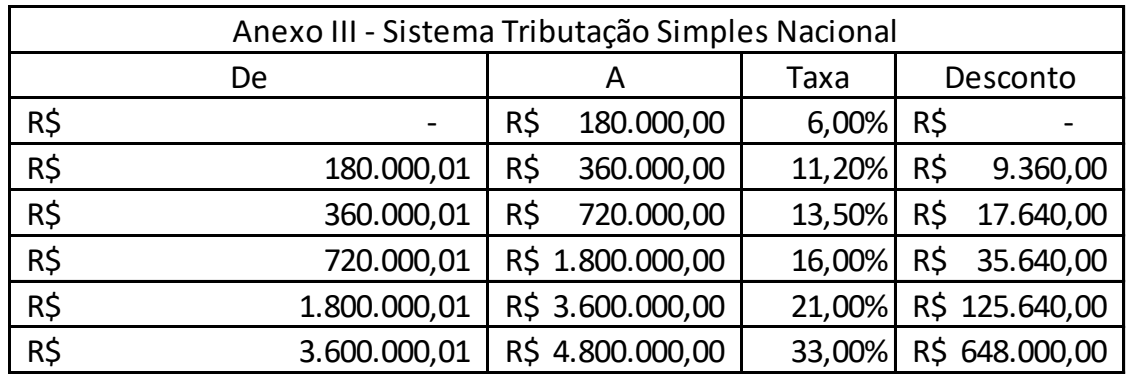

Fonte: Jornal Contábil, 2017. Adaptado.

A conta a ser feita para calcular a tributação é, portanto:

$$
\mathrm{T}_{(f)}=\left(R B \times t_{(f)}\right)-D_{(f)}
$$

Onde: 
$T_{(f)}=$ Valor de impostos a pagar em função da faixa de faturamento

$\mathrm{RB}=$ Receita Bruta

$t_{(f)}=$ Taxa de imposto em função da faixa de faturamento

$D_{(f)}=$ Desconto em função da faixa de faturamento

\subsubsection{Despesas}

As despesas operacionais e administrativas assumem a taxa de crescimento de $3 \%$ ao ano, enquanto as despesas com marketing e publicidade são calculadas como um percentual de $2 \%$ da receita do período.

\subsubsection{Depreciação}

O terreno não se deprecia, a construção se deprecia em 25 anos e os demais itens se depreciam de 5 a 10 anos. Fichas devem ser repostas anualmente (não se depreciam, entram como estoques e, depois, custos dos serviços prestados) e o capital de giro também não se deprecia. Assim, considerou-se uma depreciação média de $\mathrm{R} \$ 20.000,00$ por ano, que serão também os gastos líquidos de capital (reposição e melhorias). Uma parte destes gastos anuais de investimento (em torno de $50 \%$ ) será para melhorias, visto que a construção não pode ser reposta.

\subsection{Custo de Capital}

O projeto foi $100 \%$ custeado com capital próprio, como tem sido os modelos de negócios mais frequentes para esse mercado. A regulação ainda precária para esse tipo de negócio torna difícil a premissa da obtenção de um bom financiamento.

\subsubsection{Custo do Capital Próprio (CAPM)}

Levando em conta que o capital investido poderia estar sendo aplicado em qualquer título em qualquer lugar do mundo, e considerando a instabilidade e pouca aderência do mercado brasileiro - tradicionalmente de altas taxas de juros e excessiva volatilidade da renda variável (ativo de risco), cujo rendimento histórico é inferior à renda fixa (ativo livre de risco) - foram utilizadas premissas da economia americana para o CAPM. Deste modo, foram apurados como indicadores o rendimento médio anual do S\&P dos últimos cinco anos e a taxa 
atual dos treasuries de 10 anos, pois espelham melhor a realidade.

Os seguintes dados, extraídos da Bloomberg, foram compilados:

> Rendimento anual médio do S\&P 500 nos últimos 5 anos: 10,81\% (até 30/05/2018);

> Taxa dos treasuries de 10 anos em 30/05/2018: 2,85\%;

> Valor do CDS brasileiro de 10 anos em 30/05/2018: 3,20\% (cotação de 320 basis-points);

> Previsão da taxa de inflação dos EUA (núcleo do PCE) para 2018: 2,00\%;

> Previsão da taxa de inflação brasileira (IPCA) para 2018: 3,51\% (valor médio das projeções diárias de mercado da pesquisa FOCUS/BCB, apurado ao longo de maio, até 25/05/2018, último dado disponível para a realização dos cálculos deste trabalho).

Ressalte-se que o retorno médio anual do S\&P 500 dos últimos cinco anos está condizente com sua média histórica desde sua criação, em 1928, que é de aproximadamente $10 \%$ ao ano.

Como o financiamento foi feito integralmente com capital próprio, será usado o beta desalavancado.

Para se chegar ao CAPM em Reais, foi utilizada a seguinte fórmula de conversão:

CAPM em Reais $=[(1+$ CAPM em dólar/100 $)$ * $(1+$ CDS Brasil 10 anos/100) * $(1+$ Inflação BR/100) / (1 + Inflação EUA/100) - 1 ] * 100

Segundo Damodaran, o beta desalavancado para uma empresa no ramo do entretenimento é 0,92 . Portanto, chega-se ao seguinte resultado:

CAPM em dólar $=R f+$ beta $^{*}(R m-R f)=2,85+0,92 *(10,81-2,85)=$ $10,1732 \%$.

CAPM em reais $=(1,101732 * 1,0320 * 1,0351 / 1,0200-1) * 100=15,38 \%$.

Como o valor do endividamento é nulo, então a participação do capital próprio é de $100 \%$. Portanto, $\mathbf{W A C C}=\mathrm{CAPM}=\mathbf{1 5 , 3 8 \%}$. 
A tabela 4, adiante, resume os cálculos efetuados.

Tabela 4: Custo do Capital Próprio

\begin{tabular}{|l|c|}
\hline Treasuries 10 anos & $\mathbf{2 , 9 \%}$ \\
\hline Beta Damodaran Desalavancado & 0,92 \\
\hline S\&P 5 anos & $10,81 \%$ \\
\hline CAPM US\$ (a.a.) & $10,17 \%$ \\
\hline WACC & $\mathbf{1 5 , 3 8 \%}$ \\
\hline
\end{tabular}

Fonte: Elaborada pelo autor

\subsection{Projeção de Resultados}

Após a projeção de receitas, custos, despesas e WACC, é possível estimar os fluxos de caixa. Os indicadores utilizados para discutir sobre a viabilidade do negócio são um reflexo do comportamento destes fluxos de caixa ao longo do tempo, como já foi discorrido anteriormente.

\subsubsection{Fluxo de Caixa dos Ativos}

Existem algumas formas de medir o fluxo de caixa de uma empresa, porém para o estudo da viabilidade econômica é importante utilizar o fluxo de caixa dos ativos (FCA). Diferente de outras interpretações, como o fluxo de caixa operacional (FCO), o FCA considera também os gastos líquidos de capital ao longo do tempo e a variação do capital de giro. O cálculo do FCA leva em conta apenas custos, despesas e investimentos operacionais. Portanto, os juros pagos em função do capital de terceiros não devem ser considerados. Em resumo, dizse que: $F C A$ = FCO - gastos líquidos de capital - variação do capital de giro, onde: $F C O$ = LAJIR + Depreciação - IR.

Neste trabalho, os gastos líquidos de capital totalizam $R \$ 20$ mil por ano, como já ponderado anteriormente, e são utilizados para repor ativos depreciados e para obras de melhoria. Já o capital de giro será de $R \$ 25$ mil anuais, considerado suficiente para suportar o crescimento das receitas e do negócio.

Além de observar o valor do FCA, é preciso descontá-lo para ser comparado com valores presentes. Em outras palavras, os fluxos de hoje não são equivalentes aos futuros, e a taxa de desconto é responsável pela sua conversão ao longo do tempo, resultando no fluxo de caixa dos ativos descontado (FCAD). A soma dos FCAD, por sua vez, é o FCAD acumulado, considerando o investimento inicial e a soma de todos os fluxos subsequentes. A 
tabela 5 resume a formação do FCA, e os resultados estimados ao longo dos 20 anos estão expostos no gráfico 2.

Tabela 5: Composição do FCA

\begin{tabular}{|c|c|c|c|c|c|c|c|c|c|c|}
\hline & \multicolumn{2}{|r|}{ Ano 1} & \multicolumn{2}{|r|}{ Ano 2} & \multicolumn{2}{|r|}{ Ano 3} & \multicolumn{2}{|r|}{ Ano 4} & \multicolumn{2}{|r|}{ Ano 5} \\
\hline Receita Vendas & $\mathrm{R} \$$ & $300.000,00$ & $\mathrm{R} \$$ & $345.000,00$ & $\mathrm{R} \$$ & $396.750,00$ & $\mathrm{R} \$$ & $456.262,50$ & $\mathrm{R} \$$ & $524.701,88$ \\
\hline Receita Bruta & $\mathbf{R} \hat{\mathbf{n}}$ & $300.000,00$ & $\mathbf{R} \$$ & $345.000,00$ & $\mathbf{R} \$$ & $396.750,00$ & $\mathrm{R} \$$ & $456.262,50$ & $\mathbf{R} \mathbf{S}$ & $524.701,88$ \\
\hline Taxa \% Simples Nacional & \multicolumn{2}{|r|}{$11,20 \%$} & \multicolumn{2}{|r|}{$11,20 \%$} & \multicolumn{2}{|r|}{$13,50 \%$} & \multicolumn{2}{|r|}{$13,50 \%$} & \multicolumn{2}{|r|}{$13,50 \%$} \\
\hline Desconto Previsto & $\mathrm{R} \$$ & $9.360,00$ & $\mathrm{RS}$ & $9.360,00$ & $\mathrm{RS}$ & $17.640,00$ & $\mathrm{R} \$$ & $17.640,00$ & $\mathrm{R} \$$ & $17.640,00$ \\
\hline Tributação Simples & $\mathrm{R} \$$ & $24.240,00$ & $\mathrm{R} \$$ & $29.280,00$ & $\mathrm{R} \$$ & $35.921,25$ & $\mathrm{R} \$$ & $43.955,44$ & $\mathrm{R} \$$ & $53.194,75$ \\
\hline Receita Líquida & $\mathbf{R S}$ & $275.760,00$ & $\mathbf{R} \$$ & $315.720,00$ & $\mathbf{R} \$$ & $360.828,75$ & $\mathrm{RS}$ & $412.307,06$ & $\mathbf{R} \mathbf{S}$ & $471.507,12$ \\
\hline CSP & $\mathrm{R} \$$ & $12.000,00$ & $\mathrm{R} \$$ & $13.800,00$ & $\mathrm{RS}$ & $15.870,00$ & $\mathrm{R} \$$ & $18.250,50$ & $\mathrm{R} \$$ & $20.988,08$ \\
\hline Lucro Bruto & $\mathbf{R} \$$ & $263.760,00$ & $\mathbf{R} \$$ & $301.920,00$ & $\mathbf{R} \$$ & $344.958,75$ & $\mathbf{R} \$$ & $394.056,56$ & $\mathbf{R} \mathbf{S}$ & $450.519,05$ \\
\hline Despesas Operacionais & $\mathrm{R} \$$ & $50.000,00$ & $\mathrm{R} \$$ & $51.500,00$ & $\mathrm{R} \$$ & $53.045,00$ & $\mathrm{R} \$$ & $54.636,35$ & $\mathrm{R} \$$ & $56.275,44$ \\
\hline Marketing/Publicidade & $\mathrm{R} \$$ & $6.000,00$ & $\mathrm{R} \$$ & $6.900,00$ & $\mathrm{RSS}$ & $7.935,00$ & $\mathrm{R} \$$ & $9.125,25$ & $\mathrm{RS}$ & $10.494,04$ \\
\hline Despesas Administrativas & $\mathrm{R} \$$ & $20.000,00$ & $\mathrm{R} \$$ & $20.600,00$ & $\mathrm{R} \$$ & $21.218,00$ & $\mathrm{R} \$$ & $21.854,54$ & $\mathrm{R} \$$ & $22.510,18$ \\
\hline EBITDA & $\mathbf{R} \$$ & $187.760,00$ & $\mathbf{R} \$$ & $222.920,00$ & $\mathbf{R} \$$ & $262.760,75$ & $\mathbf{R} \$$ & $308.440,42$ & $\mathbf{R} \mathbf{S}$ & $361.239,39$ \\
\hline Depreciação & $\mathrm{R} \$$ & $20.000,00$ & $\mathrm{R} \$$ & $20.000,00$ & $\mathrm{R} \$$ & $20.000,00$ & $\mathrm{R} \$$ & $20.000,00$ & $\mathrm{RS}$ & $20.000,00$ \\
\hline EBIT & $\mathrm{R} \$$ & $167.760,00$ & $\mathbf{R} \$$ & $202.920,00$ & $\mathbf{R} \$$ & $242.760,75$ & $\mathrm{R} \$$ & $288.440,42$ & $\mathbf{R} \mathbf{S}$ & $341.239,39$ \\
\hline FCO & $\mathrm{RS}$ & $187.760,00$ & $\mathrm{R} \$$ & $222.920,00$ & $\mathrm{R} \$$ & $262.760,75$ & $\mathrm{R} \$$ & $308.440,42$ & $\mathrm{R} \$$ & $361.239,39$ \\
\hline FCO Descontado & $\mathbf{R} \$$ & $163.572,19$ & $\mathbf{R} \$$ & $169.184,98$ & $\mathbf{R} \$$ & $173.731,93$ & $\mathbf{R} \$$ & $177.662,93$ & $\mathbf{R} \mathbf{S}$ & $181.270,45$ \\
\hline Variação de capital de Giro & $\mathrm{RS}$ & - & $\mathrm{R} \$$ & $25.000,00$ & $\mathrm{R} \$$ & $25.000,00$ & $\mathrm{R} \$$ & $25.000,00$ & $\mathrm{RS}$ & $25.000,00$ \\
\hline Gastos Líquidos de Capital & $\mathrm{RSS}$ & $20.000,00$ & $\mathrm{R} \$$ & $20.000,00$ & $\mathrm{R} \$$ & $20.000,00$ & $\mathrm{R} \$$ & $20.000,00$ & $\mathrm{R} \$$ & $20.000,00$ \\
\hline FCA & $\mathrm{R} \$$ & $167.760,00$ & $\mathrm{R} \$$ & $177.920,00$ & $\mathrm{R} \$$ & $217.760,75$ & $\mathrm{R} \$$ & $263.440,42$ & $\mathrm{R} \$$ & $316.239,39$ \\
\hline FCA Acumulado & $-\mathrm{R} \$$ & $367.027,00$ & $-R S$ & $189.107,00$ & $\mathrm{R} \$$ & $28.653,75$ & $\mathrm{R} \$$ & $292.094,17$ & $\mathrm{R} \$$ & $608.333,57$ \\
\hline FCA Descontado & $\mathbf{R} \mathbf{S}$ & $146.148,65$ & $\mathbf{R} \$$ & $135.032,26$ & $\mathbf{R} \mathbf{S}$ & $143.978,87$ & $\mathbf{R} \$$ & $151.742,75$ & RS & $158.689,39$ \\
\hline FCA Desc. Acumulado & $-R \$$ & $388.638,35$ & $-R S$ & $253.606,09$ & $-R S$ & $109.627,22$ & $\mathrm{R} \$$ & $42.115,53$ & $\mathrm{R} \$$ & $200.804,92$ \\
\hline
\end{tabular}

Fonte: Elaborada pelo autor

\section{Gráfico 2: Evolução do Fluxo de Caixa dos Ativos}

$\mathrm{R} \$ 800.000,00$

RS 700.000,00

$\mathrm{R} \$ 600.000,00$

R\$̦ 500.000,00

$\mathrm{R} \$ 400.000,00$

$\mathrm{R} \$ 300.000,00$

$\mathrm{R} \$ 200.000,00$

$\mathrm{R} \$ 100.000,00$

RȘ -
RS 758.036,77

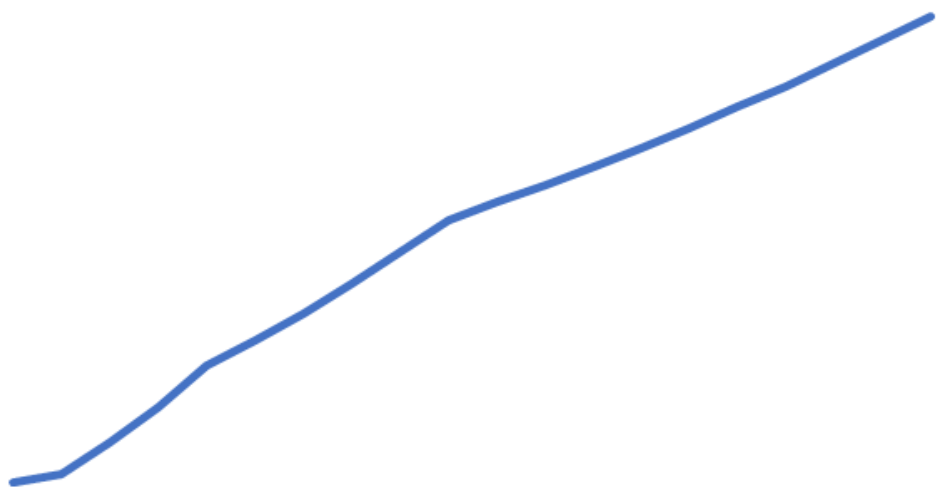




\subsubsection{Indicadores Financeiros}

A partir das informações acima, é possível calcular os indicadores de viabilidade, como o valor presente líquido (VPL), a taxa interna de retorno (TIR) e os tempos de payback e payback descontado. A análise sobre a viabilidade leva em conta o resultado destes indicadores, que dependem, em última instância, das condições em termos de premissas assumidas. A tabela 6 a seguir consolida os indicadores:

Tabela 6: Indicadores de Viabilidade Econômica

\begin{tabular}{|l|c|}
\hline \multicolumn{1}{|c|}{ Indicador } & Esperado \\
\hline VPL & R\$ 1.666.529,74 \\
\hline TIR & $23,20 \%$ \\
\hline Payback & 30 ano \\
\hline Payback Desc. & 40 ano \\
\hline
\end{tabular}

Fonte: Elaborada pelo autor

Dadas estas condições, o negócio pode ser considerado viável e muito rentável. O VPL expressivo, a TIR sensivelmente acima da taxa de desconto e o payback descontado em torno de 4 anos contribuem para uma perspectiva promissora.

Fora isso, o Retorno Econômico, calculado pela divisão do VPL pelo investimento inicial - que mostra quanto a geração de riqueza supera o investimento inicial no projeto -, é de $311,62 \%$, um valor bastante elevado. 


\section{Conclusões e Recomendações para Novos Estudos}

A partir das premissas assumidas e dados obtidos sobre o mercado de poker no Brasil, foram desenvolvidas análises para determinar a viabilidade econômica de um clube de poker no Rio de Janeiro. Foram identificados fatores que contribuem para uma expectativa promissora com relação ao projeto analisado.

O maior risco que os empreendedores poderão enfrentar é uma regulação ainda fraca e pouco sensível às especificidades do negócio. No entanto, foi possível observar que essa questão está sendo amplamente debatida e já há um viés claro no judiciário e no legislativo de grande aceitabilidade da prática do jogo.

Vale ressaltar que, com a superação da barreira do preconceito que ainda envolve o poker no Brasil, é provável que a expansão e popularização da prática do jogo sejam ainda mais aceleradas do que vêm sendo.

Como recomendação para os próximos estudos, a análise do desenvolvimento do mercado em um país que já convive há mais tempo com a existência e a proliferação de clubes de poker, como os Estados Unidos, seria interessante. 


\section{Referências Bibliográficas}

CAIO GALDI, Fernando; CAMPANHARO TEIXEIRA, Aridelmo José; BROEDEL LOPES, Alexsandro. Análise empírica de modelos de valuation no ambiente brasileiro: fluxo de caixa descontado versus modelo de OhIson (RIV). Revista Contabilidade \& Finanças-USP, v. 19, n. 47, 2008.

COPELAND, T; KOLLER, T; MURRIN, J. Avaliação de empresas - Valuation: calculando e gerenciando o valor das empresas. 3.ed. São Paulo: Pearson Makron Books, 2002.

DAMODARAN, A. Disponível em: <http://pages.stern.nyu.edu/ adamodar/>. Acesso em: 02 de setembro 2017.

Folha de S. Paulo.Clubes de pôquer crescem com público fiel e torneios diários.São Paulo,2016 Disponível em: <http://www1.folha.uol.com.br/mercado>. Acesso em: 22 de maio de 2018.

GITMAN, J. L. Princípios de administração financeira. Tradução de Allan Vidigal Hastings. 12.ed. São Paulo: Pearson Prentice Hall, 2010.

Jornal Contábil. Simples Nacional 2018: Confira as novas tabelas e limites. RiodeJaneiro,2017.Disponívelem:<https://www.jornalcontabil.com.br/simplesnacional-2018-confira-as-novas-tabelas-e-limites >. Acesso em: 02 de setembro de 2017.

Jornal Contábil. Simples Nacional 2018: Confira as novas tabelas e limites. RiodeJaneiro,2017.Disponívelem:<https://www.jornalcontabil.com.br/simplesnacional-2018-confira-as-novas-tabelas-e-limites >. Acesso em: 02 de setembro de 2017.

Jornal O Globo. Não é sorte: 0 boom do pôquer no Brasil. Rio de Janeiro, 2015 Disponível em: <https://oglobo.globo.com/esportes>. Acesso em: 26 de maio de 2018.

Jusbrasil. A legalidade dos jogos de poker no ordenamento jurídico brasileiro - Breves Considerações. 2014. Disponível em: <https://sandroalbuquerque.jusbrasil.com.br/artigos>. Acesso em: 20 de maio de 2018.

MARTINS, E [et al]. Métodos de avaliação utilizados pelos profissionais de investimento. Revista UnB Contábil da Universidade de Brasília, Brasília, 2008.

ROSS, S; WESTERFIELD, R; JORDAN, B. Fundamentos de administração financeira. Tradução de Leonardo Zilio e Rafaela Guimarães Barbosa. 9.ed. Porto Alegre: AMGH, 2013. 
ANEXO 1 - Fluxo de Caixa dos Ativos

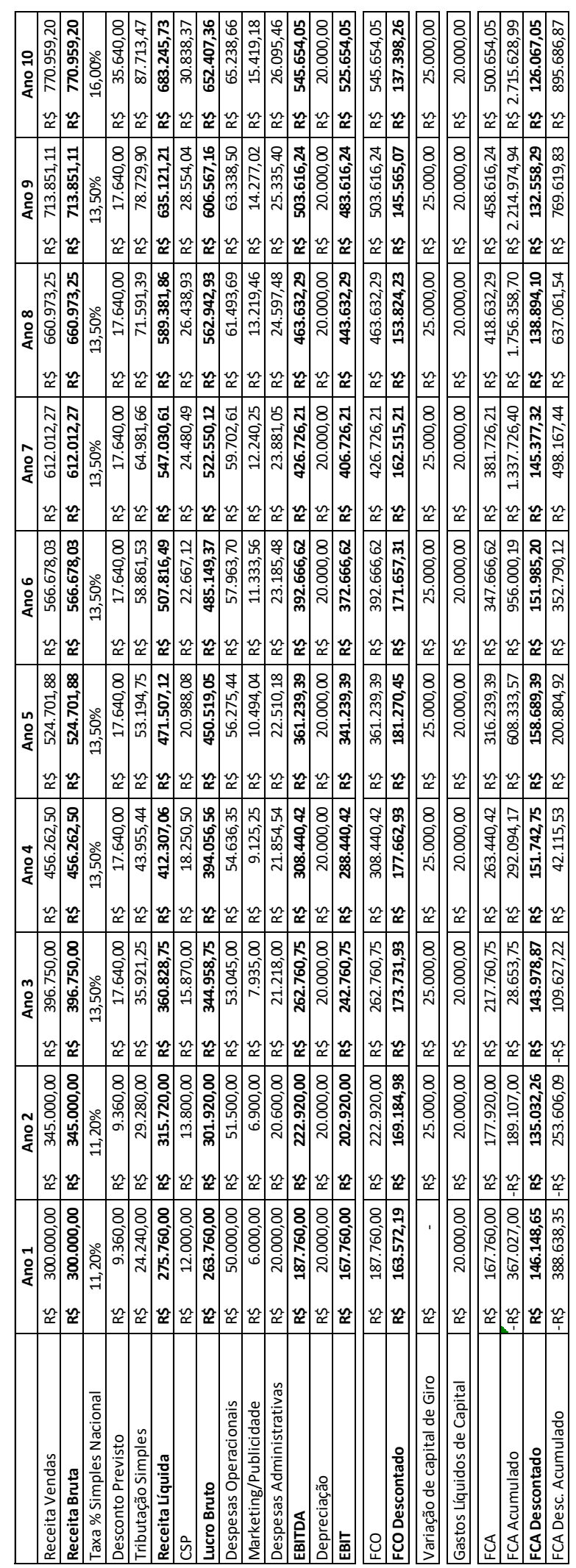




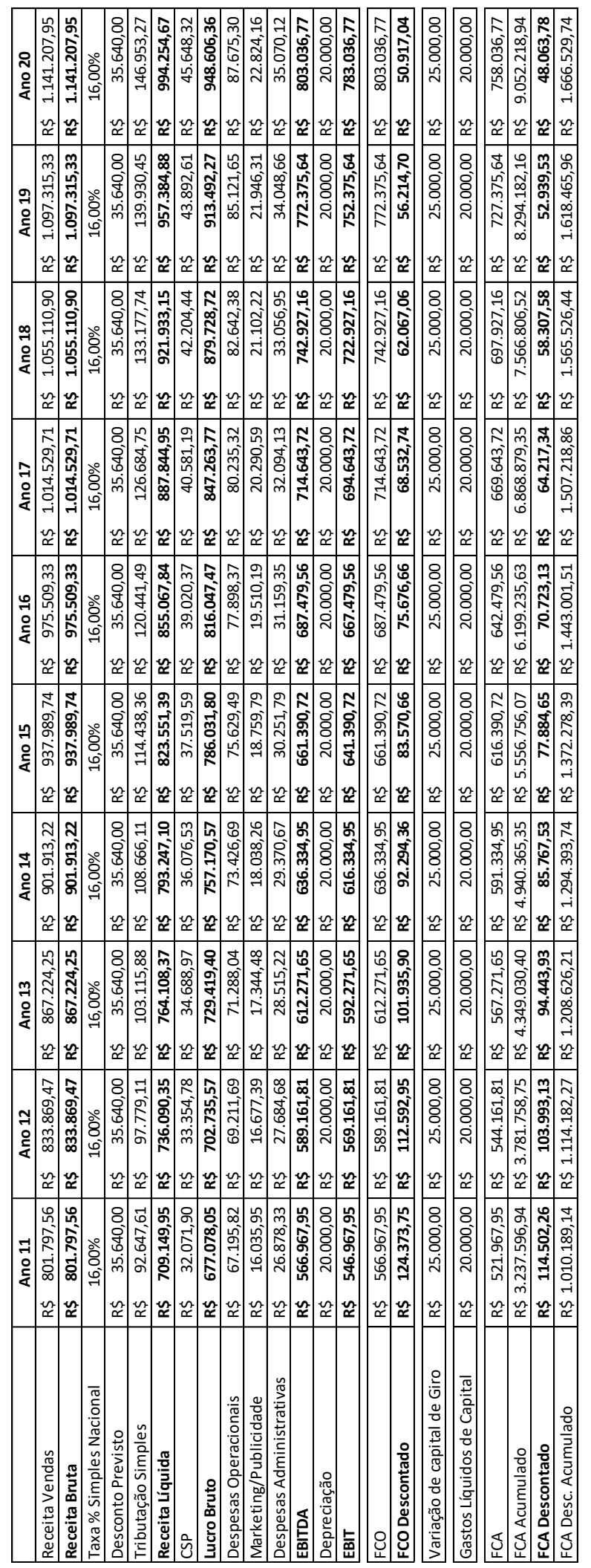

